\title{
Chinese Netizens' Reactions to Red Classics Cinema Animation A Case Study of Taking Tiger Mountain by Strategy (2011)
}

\author{
Shaopeng Chen ${ }^{1}$ \\ ${ }^{1}$ Faculty of Humanities, University of Southampton, Southampton, UK \\ Correspondence: Shaopeng Chen, Faculty of Humanities, University of Southampton, Avenue Campus, \\ Southampton, SO17 1BF, UK. E-mail: sc11g13@soton.ac.uk
}

Received: May 5, 2016 Accepted: June 9, 2016 Online Published: June 14, 2016

doi:10.5539/ach.v8n2p83 URL: http://dx.doi.org/10.5539/ach.v8n2p83

\begin{abstract}
'Red Classics' can be considered as an important subgenre of Chinese cinema animation, which is often adapted from war novels, revolutionary model opera, songs and live-action films. Animated film Taking Tiger Mountain by Strategy (2011), as a Red Classics cinema animation production, has provoked heated discussion among Chinese netizens in two largest online film communities and review aggregator sites Douban Movie and Mtime. This paper reveals the Chinese netizens' reception process of this movie before and after public screening by analysing the relevant brief comments and longer film reviews from the above two websites. Chinese audiences' expectation on Taking Tiger Mountain by Strategy was relatively negative before exhibition in cinema. This can be partly attributed to the emotional discontent over the previous Chinese animation and government intervention on artistic creation. However, there has been a gradual shift in the attitudes of netizens towards this movie after the public exhibition, the reviews have become more objective, rational and positive. This article aims to identify the reasons behind such attitude change by applying reception studies approach, and how and to what extent these elements have affected Chinese netizens' evaluation process.
\end{abstract}

Keywords: Chinese animation, Red Classics, netizens, expectation, attitude shift

\section{Introduction}

The so-called 'Red Classics' (Hong Se Jing Dian/红色经典 in Chinese) is widely considered as a Post-cultural Revolution (note 1) terminology with a huge controversy in China. Official perspective considers Red Classics as 'literary works with revolutionary and historical themes which have caused large repercussions nationwide' (State Administration of Press, Publication, Radio, Film and Television of The People's Republic of China, 2004). It is generally acknowledged that Red Classic works not only include revolutionary model operas which were created during the Cultural Revolution, but also a series of literary and artistic exemplary productions. The above works were produced under the guidelines of the spirit of Mao Zedong's 'Talk at the Yan'an Conference on Literature and Art', in order to reflect social and political movements under the leadership of Chinese Communist Party, as well as lives of ordinary peasants and soldiers. However, critics and academics have varying opinions in terms of its original implication and relevant cultural phenomenon. Professor Chen Sihe maintains that the 'Red Classics' is an inherently vague concept. The extensive spread of 'Red Classics' is, in essence, the deconstruction and mockery on 'classics' as a term has value judgement meaning, especially for its application on revolutionary models operas, which he argues as a kind of 'freak' produced under the absurd extreme leftist literary and artistic principles (Zhang, 2004). Unlike Chen's totally repudiation of this genre by denying its aesthetic and social value, Professor Liu Kang believes that Red Classics creations are, 'at once a corpus of literary and artistic works about the Chinese Revolution of the pre-PRC period (1920s-1940s), and a massive cultural production from the 1950s to the 1970s' (Liu, 2010). Similarly, Dr Tao Dongfeng affirmed the reasonableness of Red Classics from the perspective of semantics. He argues that the colour red especially bright red features explicit political implication in the context of Chinese contemporary history which represents socialist revolution, and a symbol of the Chinese Communist Party (Tao, 2004).

It is important to clarify the meaning and characteristics of the accurate definition of Red Classics Cinema Animation (henceforth referred to as RCCA) at this point, in order to lay a foundation for the following sections. The majority of RCCA productions refer to animated feature films adapted from the Red Classics live-action films, operas or literary works under the same name, such as Little Solider Zhangga/小兵张嘎 (Sun, 2005) and Taking 
Tiger Mountain by Strategy/智取威虎山 (Chen, 2011) (henceforth referred to as TTMS), while others tend to expand original stories that based on Red Classics text, which are represented by Xi Bai Po/西柏坡 (Wang, Lu, \& Yin, 2011) and Bugle Calls/冲锋号 (He, 2013). TTMS expands the same name chapter in war novel Tracks in The Snowy Forest/林海雪原 (Qu, 1957). This novel is widely considered as the representative work of RCCA. The plot of TTMS is based on a true account occurred in 1946 during the second Chinese Civil War, a communist officer Yang Zirong who infiltrating a group of local bandits, after a battle of wits, eventually helping the party's large force to destroy the bandits.

The key aim of this article is to analyse the Chinese netizens' reception process towards TTMS by engaging in the reception studies approach, then to consider this movie in the context of struggling Chinese animation industry. The article will start by a brief introduction of the history and status quo of Chinese animation, and then follow by an analysis of how Chinese spectators make sense of Little Solider Zhangga, which is the first RCCA work in mainland China; The main section focuses on the netizens' attitude change towards TTMS from the expectation stage to theatrical release, this analysis is based on the interpretation of reviews from Douban Movie and Mtime which are the two largest Chinese online film databases and movie review aggregation sites.

\section{The General Overview of Chinese Audiences reactions to Domestic Cinema Animation}

Chinese cinema animation had achieved not only global reputation but enjoy domestic popularity for a long period. A series of animated films are labelled as 'Chinese School', which Yin Yan argues 'the so-called "Chinese School" is a kind of nationalization Chinese cinema animation with distinctive national characteristics and artistic expression principles, meanwhile inherits ethnic cultural and historical heritage in China' (Yin, 1988). Chinese animation won approximately thirty awards from international animated film festivals such as Annecy and Zagreb (Anonymous, 1984). Since the founding of PRC in 1949 until 1980s, the only production unit of 'Chinese School' cinema animation in mainland China is the state-owned Shanghai Animation Film Studio which had a considerable scale, according to Bendazzi, 'in 1956, the studio included 200 workers and by the 1960s they had grown to include 380' (Bendazzi, 1994).

However, Animation production suffered massive impact during the Cultural Revolution (1966-1976). The whole film sector carried out the 'Four Clean-ups Movement' (note 2) as soon as the Revolution began. A series of works which included cinema animation were condemned as 'poisonous weeds' and were then banned. Bendazzi continues, 'the Shanghai studio was closed in 1965, the filmmakers were sent to educational camps and the studio did not open until 1972' (Bendazzi, 1994). During this period, artistic and literary works 'only featured both socialist-minded and professionally competent factors' (Yang, 1997) could pass the strict censorship by the cultural departments such as the Ministry of Culture and the Revolutionary Committees, majority of productions were known as Red Classics.

Since 1995 the creation of Chinese animation has freed itself from the rigid panned economy system and get involved into the market competition, accordingly the production and operational model of cinema animation have undergone great changes. However, in spite of abnormal high production capacity of cinema animation and its TV series counterparts (note 3), Chinese animation has started to encounter a series of problems such as 'low-level quality' and 'lack of Chinese stories and a propensity to imitate' (Lent \& Xu, 2010). This paradoxical phenomenon can be attributed into three main reasons: firstly, a number of Chinese animation studios are being engaged in the outsourcing work from its overseas counterparts which are mainly come from Japan or United States. The intensive outsourcing work has been leading to the scarcity of creative talents in the whole sector especially for the screenwriters and storyboard designers. Secondly, in most cases, cartoon characters in Chinese animation, whether human beings or animals, are lack of unique personality and thin as flimsy. Furthermore, animation creations are still overemphasizing its educational function while ignoring the most fundamental entertainment features.

The inferior quality leads to the disaffected sentiment of the audience directly. There has been a heated debate about the status quo of Chinese animation on the internet, netizens who Jenkins maintains as 'not by being a regular viewer of a particular program but by translating that viewing into some type of cultural activity, by sharing feelings and thoughts about the program content with friends, by joining a community of other fans who share common interests' (Jenkins, 2004), consider the Chinese animation not only disappointing at present stage, but hopelessness in the future, some of whom even using the term "garbage" to describe contemporary Chinese animation. In a newspaper article, a family life scene depicted by a journalist reveals that " $I$ (the author) myself am a fan of comics and animation and always watch cartoons with my son, I have found that he is much more exciting and keep giggling while watching foreign animation. On the contrary, he often becomes silent and listless immediately once the domestic animation begins to display. I believe the main reason is that the vast majority of Chinese animation products 
deviated from the animation's basic attribute as an amusement media and entertainment features, instead it slid to an extreme-one-sided focus on the indoctrination function as a tool of education'.

Plagiarism is another serious problem. An observer listed ten apparent plagiarism cases of Chinese animation which partly or completely copy classics animation works abroad in an online animation forum, this list demonstrates the severity of the plagiarizing. According to a recent online mass observation organized by a Chinese animation magazine Chinawao which is based in Shanghai, 19 of 20 most popular cartoon characters among Chinese adolescents are from Japan, the only representative of domestic animation is Sun Wukong (note 4), which means no contemporary Chinese animated characters included in the list. Even several industry practitioners also reveal pessimistic attitude towards the present situation of Chinese animation. For example, dean of Animation School of Communication University of China Lu Shengzhang denounced that '18, 0000 minutes of Chinese animated TV series are rubbish, which can be partly attributed to the majority of them are far from reality and lack of credible details.'

Similar to the audiences' attitude towards the animation creation in China, the reactions to RCCA biased towards the negative aspects in most cases. Little Solider Zhangga is the first animated feature film that is classified as RCCA, this film was released in 2005 and directed by Sun Lijun. Although it was nominated for the best animated film in the 26th China Golden Rooster Awards and won Annual Outstanding Animation in China Huabiao Awards (note 5), netizens maintain that it do not deserve such important honours. According to a recent mass observation which had send out 300 electronic questionnaires to netizens in Guizhou province of China, 34.6 per cent of respondents have seen Little Solider Zhangga, among them only 9.7 per cent considered the animated film is 'exceeding expectations' and 'worth watching repeatedly'; while its 'barely satisfactory' and 'unsatisfactory' counterparts accounted for 35.6 per cent and 46.4 per cent respectively. The rest of the participants who have seen the movie maintain it 'do not worth watching'. Most of the respondents are dissatisfied with the animated figure's stiff movement in the joints, meanwhile the excessive similarity of dubbing for completely different characters made their personality less prominent.

\section{Chinese Expectations on TTMS before Exhibition}

As mentioned in the introduction section, in mainland China there are two largest online databases of films named Douban Movie and Mtime, they both not only include the information about cast, production crew and distribution companies in the home page of each work, but also served as the review websites which are based on the rating system that ten is the perfect score. Douban Movie and Mtime enable Chinese netizens exchange their views and post comments on it. Jenkins describes this type of fan behaviour as 'a particular set of critical and interpretive practices' (Jenkins, 1992), which Staiger interprets as 'fans usually have developed a network of colleagues, and these groups discuss, debate, and, for newcomers, teach perceptions of variation among the formulas, explanations for the aspects of the text of performance, and predictions of future encounters with it' (Staiger, 2005). Therefore the above two websites can also be considered as social medias for filmgoers. Marich maintains that social media can quickly aggregate moviegoers and online comments become more critical once films are in theatres by adopting case studies on Disney and Paramount's social network marketing (Marich, 2013). Davis, Dickinson, Patti and Villarejo also note the role of social media and its viral effect in information dissemination, which 'has revitalised the important of word-of-mouth marketing in the film industry' (Davis, Dickinson, Patti, \& Villarejo, 2015). Chinese netizens' reviews from both sites can be broadly divided into two categories: namely the brief comments which contain a few sentences or just several key words, and longer and more systematic film review. On the one hand, similar to the Internet Movie Database (IMDb), Douban Movie and Mtime have a points-scoring system which indicates overall evaluation of individual film. On the other hand, unlike IMDb, both of them add an expectation scoring and commenting subsystem, which means netizens are able to score then post their reviews towards a film before the latter's public screening. In other words, people can judge a film even without seeing it. In many cases, the evaluation process of expectation score is influenced by the reputation of the director and protagonist of a movie or the attribute of the genre, the latter factor is more influential on cinema animation.

TTMS was released in the last day of 2011, after two weeks exhibition in mainland China, this movie earned approximately 2.41 million Chinese Yuan in box office and 15,214 spectators have seen it the cinema. Before the public screening of TTMS, the expectation score of TTMS on the online movie review aggregations presented a trend of polarization. Specifically, in TTMS' home page within Douban Movie, the rating system is comprised by five classes, namely the five-star grade (strongly recommended), four-star grade (recommended), three-star grade (barely satisfactory), two-star grade (unsatisfactory), and one-star grade (strongly unsatisfactory). Before public screening there were 49 netizens showed their attitude to the movie and only 2 of them appraised it as 'five-star expectation' while others asserted it as 'one-star', other three grades were completely blank. The reason of such a huge contrast can be revealed from the brief comment aspect. The assessment process of TTMS was significantly 
affected by audiences' omnipresent discontent sentiment towards artistic standards and present situation of Chinese animation, in extreme cases, some commentators gave the movie one-star grade expectation even without have seen the trailer. This kind of mood can be interprets as Jenkins said 'far beyond the information explicitly present and toward the construction of a meta-text that is larger, richer, more complex and interesting than the original series' (Jenkins, 1992), therefore it can be argued that criticism from netizens is arbitrariness, non-rational and subjective in this period:

The reason why I give TTMS one-star is not only for the movie itself, but also for the hopeless Chinese animation industry that without entrepreneurial spirit and lack of creativity. (@YeXu Qing Chun Zheng Nian Shao)

Having seen the trailer of this animated film, I was just wondering why the artistic and painting styles of the Chinese cinema animation are all the same. I believe the only option for me is one-star. (@Anguine)

I think it is an eternal truth that main melody (note 6) plus Chinese animation equals annual lousymovie. (@LeiGao Cheng)

I have not seen this film but I know it will be awful because it is belong to the Chinese animation.(@Dunn)

Have not watched the film but it does not matter. I will rate it one-star. (@Qiuxin)

Noexplanation (one star) (@moody)

I am here for giving this film one-star, do not ever tell me like you are not qualified for reviewing this film because you have not watched it'. Why should I eat shit if I know what it is?(@ong Kou Gong Kou Xiao Huang Men)

Since the establishment of Chinese Communist Party in 1921, the production of literary work within the so called 'Liberated Area' (note 7) has long been perceived as a propaganda tool served for the political purpose, which mainly focus on reflecting the positive and progressive daily lives of workers, peasants and soldiers, while exposing the atrocities of the enemies such as Japanese invaders, Kuomintang troops and local bandits. After the founding of the PRC in 1949 by Communist Party, creation of artistic and literary works has not only needed to follow the above principles, but also added educational elements gradually and intentionally. As for the animation production aspect, the Ministry of Culture proposed a slogan that 'animation should serve for the children' (Te, 1984). Since then the production and exhibition of animation has gradually become a tool of child education and indoctrination. It should be noticed that in most cases, the excessive rigid and simplified preaching has resulted in resentment of the audience, especially for their attitude towards Red Classics texts such as drama, novel, opera, song, film and animation. This phenomenon can be illustrated by netizen's review on of TTMS on Douban Movie:

The production of RCCA is just a political task which imposed by the government, more importantly it can get generous subsidies from cultural authorities. (@Gugu)

Actually I think RCCA is a form of party lecture which disguised under the form of animation. (@Jarodyeung,)

I was just wondering the production incentive of TTMS, is it an attempt to please the senior government leaders in Beijing? (@Folk Lord,)

Compared to the Chinese netizens reactions to TTMS on Douban Movie, expectation on Mtime showed a similar scenario. In the homepage of TTMS, the expectation point of the movie marked as 3.3 within a ten-point system which means 'mediocre creation, do not worth watching'. However, with the exhibition of TTMS and later transmission of its online video version, attitude of the audience has shifted gradually.

\section{Chinese Netizens' Reactions to TTMS after Theatrical Screening}

TTMS was released on 31 December 2011, despite the unsatisfactory box office after two weeks exhibition in the cinema, Chinese reactions to it has witnessed a steady changes on the internet. Although the overall rating of TTMS is still relatively lower than the majority of American and Japanese cinema animation, the distribution of 
evaluation grade indicates a more balanced trend compared to its expectation counterparts. On the homepage of TTMS in Douban Movie, 82 netizens have rated and then posted a piece of brief comment for the movie after exhibition up to 1 December 2013. In spite of one-star grade still account for the largest proportion of the total evaluation (26), other options have witnessed an increasingly share. Specifically, the number of netizens who chose two-star, three-star and four-star grade have risen dramatically from completely blank to 16,15 , and 11 respectively, which constitute 20 per cent, 18 per cent, and 13 per cent separately. In terms of its five-star counterparts, it was account for 18 per cent (14). Simultaneously, after watching the full-length version of TTMS, although there are still considerable reviews towards the movie from Douban Movie and Mtime, audiences' attitude has also undergone an obvious transformation and become more objective and rational, which can be revealed from the brief comment aspect:

After browsing the expectations of TTMS from netizens, I was pretty curious and wonder how terrible Chinese cinema animation could be, so I went to the cinema to watch this film yesterday. Surprisingly, I was totally shocked by the movie and the 2D pure hand-painted scenes. They are absolutely spectacular! I just don't know why others deliberately belittle TTMS. (@WuDa Jie Kong)

This is a great movie! Come on, Chinese animation! (@Qi Mao)

Although the creation of squirrel in TTMS is suspected of plagiarism for its counterpart in Ice Age, I think the overall quality of this movie is satisfactory. (@Night of Mass)

Fairly speaking TTMS is exceeding expectations, some anthropopathic animal characters are adorable and playful, I think we should pay more tolerance and patience on the Chineseanimation. (@BeiADuoLiQie,)

I watched TTMS with my younger brother and I have not seen Chinese animation for a long time. Unlike other RCCA in China. I think TTMS express complicated history before the founding of PRC in a more acceptable and natural way. In addition, the educational elements in this movie are not much stiff as its RCCA counterparts. (@Si Xi Wan Zi)

Ignoring the political factors, TTMS is suitable for kids, my son was very exiting while watching this movie. (@Yunyan,Xian,Shanxi Province)

Staiger argues that 'personal memories may be couched in general or specific language of recollection' (Stagier, 2005). This kind of assertion can be verified by the reception process of TTMS from pre-exhibition to public screening. Some netizens, who spent their childhood during the period of Cultural Revolution, regard Red Classics literary and artistic works especially revolutionary model operas as a part of their collective memory. A large quantity of lines, plots, costumes, tableaux and postures in model operas have been widely spread and being deemed as the mark of an era. Therefore nowadays reproduction of Red Classics works is more likely to be accepted by middle-aged audience. As discussed earlier, TTMS and Tracks in The Snowy Forest are one of the most important RCCA works, which have been adapted to film, TV series, revolutionary model operas and stage play. Audiences' emotion on TTMS has been directly reflected on their attitude towards the animation version as a classics text.

I am 46 years old and I have watched revolutionary model opera TTMS for many times. The heroic image of the protagonist Yang Zirong has been enjoying cross-generational support. As soon as I watched the animated image of Yang on the screen, the familiar costume and styling evoked my memories of the past. (@Qin Wang Mu Ge)

Watching animated film TTMS is a very good approach for understanding Chinese Civil War, in the meantime the form of animation could be more acceptable by our next generation children. (@Yan Zhong Jing Shen Kao Kao Jun)

The classic dialogue 'Tian wang gai di hu, bao ta zhen he yao' reminds me a childhood game that I played as the protagonist Yang Zirong while my little buddy as the antagonist Zuo Shandiao. (@Virgo Palace) 
Different from the relatively speculative and subjective expected rating and brief comments in Douban Movie and Mtime, longer film review cannot be issued until the movie's release. As a result, it tend to conduct a more comprehensive and objective interpretation of the movie. As for the case of TTMS, there are four longer film reviews within Douban Movie, two of them give TTMS three-star evaluation while others are two-star. Among them a review titled 'Generally speaking, TTMS is worth watching for children above eight years old' maintains that:

It is well-known that now a lot of people are so disgusted with the Red Classics works. Obviously they will vote to against TTMS even they have not seen the full-length version of the movie. However, from my point of view, despite some childish and unreasonable plots and the lack of introduction of the context, I consider this movie exceeded my expectations.

Firstly, although the theme of the film is counterinsurgency, but the scene is pretty mild, neither bloody nor violence. After watching the movie, my son said happily to me that: 'I like this kind of cinema animation best because good people have survived and all the bad guys were being caught.' Secondly, I find that scenery within the movie is delightful, especially the depiction in snowy forest in North eastern China. Lastly, TTMS is very concerned about the harmonious coexistence of human and nature, in the meantime several adorable animal characters are popular among children. (@boovie)

Longer film review issued from Mtime illustrates a parallel situation. On this site the most popular commentary is 'TTMS - An Amusing Chinese RCCA Full of Sincerity' which has attracted 63 replies. It interprets this movie from three aspects: to begin with, the author maintains that characters within TTMS, whether protagonists or antagonists or anthropopathic animals, demonstrate their distinctive personality; following this, as a realistic themes animated film which reflects the history of counterinsurgency, the plot of TTMS is neither tedious or too straightforward but full of recreational factors and action scenes; finally, as a cinema animation adapted from Red Classics works, TTMS shows the integration of three animation genre (historical, fantasy adventure and spy game respectively), which caters to the theme of romanticism and heroism. Above all, it is a courageous attempt for Chinese cinema animation. This movie review is recognized by majority of netizens who post their ideas about the movie to make some supplementary towards the views from the author.

\section{Conclusion}

To conclude, Chinese cinema animation has been struggling to survive in the recent two decades. A variety of disadvantages directly lead to the current difficulties such as talent shortage, pale image of characters and stiff educational elements. As a result, in spite of some barely satisfactory works, Chinese netizens are losing patience towards Chinese cinema animation gradually given the continued deterioration of artistic quality and commercial value, many of the domestic animated films are even dismissed as 'garbage'. In China's two largest movie communities Douban Movie and Mtime, this type of habitual thinking can be revealed in the reception process of TTMS as a Red Classics cinema animation production. Due to the audiences' disappointing even despairing sentiment for previous Chinese cinema animation while mixed with the dissatisfaction with the behaviour of government intervention, the expectation of Chinese netizens to TTMS was relatively negative which can be reflected from the expected score and brief review aspects. It can be argued that some commentators are dominated by irrational mood, they rated the movie as one-star grade even have not seen the trailer.

However, such unintentional prejudice has shifted gradually since the theatrical release of TTMS and the widely dissemination of its online video version. Compared with the pre-exhibition period, grade distribution has showed a more balanced trend. In the meantime, most comments issued by netizens, either brief or longer ones, are becoming increasingly rational and objective and tend to focus on discussion of the content of TTMS instead of simply emotional release. At the same time, the limitations of this research should be noticed that the scope of investigation confined to two largest online movie communities in mainland China, this means that sources about TTMS are relatively limited to specialized online film communities. Although the reviews from these sites do represent the mainstream opinions on this film and RCCA, but some comments within other websites may have been ignored. In the following study, wider range of resources will be collected in order to obtain a more comprehensive analysis about Chinese netizens reactions to RCCA.

\section{Acknowledgments}

The study was funded by the China Scholarship Council (CSC). 


\section{References}

Bendazzi, G. (1994). Cartoons: one hundred years of cinema animation. London: John Libbey.

Boovie. (2011). 就片论片, 8 岁以上的孩子还是可以看一看的 (Generally speaking, this film is worth watching for children above eight years old). Retrieved from https://movie.douban.com/review/5239113/

Cappuccino. (2010). 专家炮轰中国原创动画 “18 万分钟的动画都是垃圾” (Specialist criticizes Chinese animation: 18,0000 minutes of Chinese animation are rubbish). Retrieved from http://www.comicyu.com/ html2010/49/2010/43010.html

China Box Office. (2016). 智取威虎山 (动画版) (Taking Tiger Mountain By Strategy: animation version). Retrieved from http://www.cbooo.cn/m/589321

Davis, G., Dickinson, K., Patti, L., \& Villarejo, A. (2015). Film studies: a global introduction. London: Routledge.

Douban Movie. (2016). 智取威虎山 (2011) (Taking Tiger Mountain By Strategy 2011). Retrieved from https://movie.douban.com/subject/10343115/

Gamesky. (2014). 无节操抄袭秀下限 天朝史上十大最具争议动漫 (Ten cases of suspected plagiarism Chinese animation). Retrieved from http://www.gamersky.com/wenku/201402/335231.shtml

Jenkin, H. (1988). Star Trek rerun, reread, rewritten: Fan writing as textual poaching. Critical Studies in Mass Communication, 5(2), 85-107. http://dx.doi.org/10.1080/15295038809366691

Jenkins, H. (2013). Textual poachers: television fans \& particular culture. New York and London: Routledge.

Lent, J., \& Ying, X. (2010). Chinese animation film. In Y. Zhu \& S. Rosen (Eds), Art, politics, and commerce in Chinese cinema (pp. 111-125). Hong Kong: Hong Kong University Press.

Li，L. (2009). 中国孩子喜欢的 20 个动漫形象中 19 个来自日本 (19 of 20 most popular cartoon images among Chinese adolescent are From Japan). Retrieved from http:/news.xinhuanet.com/newmedia/ 2009-04/14/content_11181823.htm

Liu, K. (2010). Reinventing the 'Red Classics' in the age of globalization. Neohelicon, 37, 327-347. http://dx.doi.org/10.1007/s11059-009-0031-3

Luo, J. (2012). 红色文化题材的动画创作研究 (Research on animation creation with red culture theme) (Unpublished master's thesis). Gannan Normal University, Ganzhou, China.

Mao, C. (2011). 垃圾产品堆出了第一动漫大国 (The 1st rank animation powerhouse is comprised by waste products). China Youth Daily, p. A2.

Marich, R. (2013). Marketing to moviegoers: a handbook of strategies and tactics (3rd ed.). Carbondale: Southern Illinois University Press.

Mtime. (2016). 智取威虎山 (2011) (Taking Tiger Mountain by Strategy 2011). Retrieved from http://movie.mtime.com/158175/

No Author. (1984). 附录 2 (Appendix 2). In Editorial office of movie communication in the film bureau of cultural department \& National film editorial office in China film press (Eds), 美术电影创作研究 (Research on the fine art film) (pp. 194-196). Beijing: China Film Press.

Ren Shi Dian Ying. (2012). 《智取威虎山》: 趣味篮然满诚意的中国动画 (Taking Tiger Mountain By Strategy - an amusing Chinese animation full of sincerity). Retrieved from http://movie.mtime.com/ 158175/reviews/7247299.html

Staiger, J. (2005). Media reception studies. New York and London: New York University Press.

Tao, D. (2004). 红色经典:在官方与市场的夹缝中求生存 (下) (Red Classics: struggling between the official intervention and market competition second part). Comparative Literary in China, 57(4), 32-48

Te, W. (1984). 美术电影创作放谈 (Talking about the creation of fine art film). In Editorial office of movie communication in the film bureau of cultural department \& National film editorial office in China film press (Eds), 美术电影创作研究 (Research on the Fine Art film) (pp. 1-11). Beijing: China Film Press.

The State Administration of Press, Publication, Radio, Film and Television of the People's Republic of China. (2004). 国家广电总局: 关于“红色经典”改编电视剧审查管理的通知 (Issues related to the censorship and regulation of TV series adapted from 'Red Classics'. Retrieved from http://news.xinhuanet.com/ newmedia/2004-05/31/content_1499380.htm 
Yang, F. (1997). 关于"又红又专"问题的历史评价 (The historical judgment of the issue of "Socialist-minded and Professionally Competent"). Journal of Chinese Communist Party History Studies, 344(4), 56-61.

Zhang, S., \& Gong, J. (2010). 谁创造了《小蝌虫找妈妈》：特伟和中国动画 (Who creates Little Tadpole Looking for Their Mom: Te Wei and Chinese animation). Shanghai: Shanghai People's Publishing House.

Zhang, Y. (2004). 陈思和: 我不赞成"红色经典"这个提法 (Chen Sihe: I do not agree with the proposition 'Red Classic'). Southern Weekly, p. A11.

\section{Notes}

Note 1. The Cultural Revolution is a social-political movement lead by Mao Zedong and the left wing of Chinese Communist party, this campaign is then publicly disavowing by the party. It also called 'Ten Years of Chaos' or 'Ten-year Catastrophe' in China.

Note 2. The Four Clean-ups Movement refers to clean thinking, clean politics, clean organization and clean economy respectively.

Note 3. According to Chinese animation industry association, total output of TV series animation in mainland China was 26, 0000 minutes in 2011 and ranked 1st around the world, meanwhile the production of cinema animation also reached the record high as 89 units.

Note 4. Sun Wukong is the male-monkey-like main immortal character in traditional Chinese supernatural evil-spirit novel Journey to the West (written by Wu Chengen in the sixteenth century), this character is the narrative and visual symbol of Chinese animation in the 'Chinese school' era.

Note 5. The Ornamental Column Awards is hosted by The State Administration of Press, Publication, Radio, Film and Television of the People's Republic of China, and the Golden Rooster Awards is organized by China Film Association and China Federation of Literary and Art Circles. They are the most authoritative and professional film awards in mainland China.

Note 6. The 'main melody' here means Red Classics literary works.

Note 7. Liberated area refers to the areas controlled by Chinese Communist Party and their army during the Second Sino-Japanese War and Second Chinese Civil War. The latter is between Nationalist Party (Kuomintang, or KMT) and Chinese Communist Party.

\section{Copyrights}

Copyright for this article is retained by the author(s), with first publication rights granted to the journal.

This is an open-access article distributed under the terms and conditions of the Creative Commons Attribution license (http://creativecommons.org/licenses/by/3.0/). 